\title{
Figures and Tables
}

\section{Figures}

Figure 1.1 A graphical rendering of the main concepts related to complex systems $\quad 12$

$\begin{array}{lll}\text { Figure 1.2 A logistic map } & 14\end{array}$

$\begin{array}{lll}\text { Figure 1.3 Problems and their characteristics } & 15\end{array}$

Figure 2.1 The Ptolemaic model of the solar system and the deferent/epicycle model for the motion of a planet 23

$\begin{array}{lll}\text { Figure 2.2 Drawing of a medieval planispheric astrolabe } & 23\end{array}$

$\begin{array}{lll}\text { Figure 2.3 Level of aggregation and modelling technique } & 27\end{array}$

Figure 2.4 System dynamic representation of strategy adoption 28

Figure 2.5 Representation of the system dynamic model as an agent-based model 29

Figure 2.6 Representation of the model building process 30

Figure 2.7 A schematic view of modelling and simulation 42

$\begin{array}{lll}\text { Figure 3.1 The city of Cremona, Italy } & 47\end{array}$

Figure 3.2 The conceptual mode of local food consumption

(A) and the outcomes of its empirical verification (B) 50

Figure 3.3 Schematic view of the main classes of ML techniques 57

Figure 3.4 Schematic view of a machine learning model implementation $\quad 59$

$\begin{array}{lll}\text { Figure 3.5 Rapidminer workflow } & 60\end{array}$

Figure 3.6 Most frequent origins of Cremona visitors 62

Figure 3.7 Most frequent destinations for Cremona visitors $\quad 62$

Figure 3.8 A simple network with its adjacency matrix 63

Figure 3.9 The Cremona network and its cumulative degree distribution 68

Figure 3.10 Average clustering coefficient as a function of degree 69 
$\begin{array}{lll}\text { Figure 3.11 Modularity analysis of Cremona network } & 70\end{array}$

Figure 3.12 The NetLogo diffusion model 74

Figure 3.13 Simulation results: (A) the cumulative distribution of infected individuals and (B) the differential distribution

Figure 3.14 Causal loop diagram

75

Figure 3.15 Stock and flow diagram $\quad 76$

$\begin{array}{lll}\text { Figure 3.16 } & \text { CLD for a Bass diffusion model } & 76\end{array}$

Figure 3.17 Stock and flow diagram for the Bass model 77

Figure 3.18 Bass model outcomes when changing simulation parameters $\quad 77$

$\begin{array}{lll}\text { Figure 4.1 Graphlets examples } & 85\end{array}$

$\begin{array}{lll}\text { Figure 4.2 Multilayer network } & 88\end{array}$

Figure 4.3 Multilayer network with its supra-adjacency matrix representation

Figure 4.4 Layered network and examples of micro-configurations (motifs) 91

Figure 4.5 Representation of an artificial neuron $\quad 96$

Figure 4.6 A simple neural network 96

Figure 5.1 Balancing the confidence and complication of a model 105

Figure 5.2 Problem statements, data and modelling techniques 117

Figure 6.1 NetLogo interface of the model implementation 126

Figure 6.2 Difference between observed and simulated tourist flows from country $i$ to country $j$

Figure 6.3 Rapidminer operators for the prediction of cancellations

Figure 6.4 Rapidminer setting for the application of a model on $\mathrm{H} 2$

Figure 6.5 Prediction of cancellations

Figure 6.6 Correlation between hotels' occupancy and quality of network position

Figure 6.7 Schematic representation of the system dynamic model

Figure 6.8 NetLogo system dynamic build and model interface implementation

Figure c.1 Interrelation between cognitive acts without (A) and with (B) action and model of values 148

Figure c.2 A possible approach for studying tourism systems 


\section{Tables}

Table 1.1 Characteristics of simple, complicated and complex systems

Table 3.1 A conceptual model for tourism activities and governance in Cremona

Table 3.2 Opinions on Cremona $\quad 54$

Table 3.3 Regression model results $\quad 55$

Table 3.4 Sample from the input data set $\quad 60$

Table 3.5 Sample association rules for travellers coming to Cremona

Table 3.6 Sample association rules for travellers outgoing from Cremona

Table 3.7 Cremona network composition

Table 3.8 Main Cremona network metrics

Table 3.9 Most relevant actors in the Cremona network

Table 5.1 Generalised problem statement and preferred modelling technique

Table 5.2 Main features defining the quality of data

Table 5.3 Data type and availability and preferred modelling technique

Table 6.1 Fitness ( $\mathrm{ff}$ ) and average traveller's discrepancy between simulated and observed (Avg $\triangle$ Pop) data for the top 10 fitness evaluations

Table 6.2 Fitness (ff) loss when changing parameters by $10 \% \quad 130$

Table 6.3 Confusion matrices for the data set H1 136

Table 6.4 Confusion matrices for the data set $\mathrm{H} 2$

Table 6.5 Percentage difference between models for H1 and H2 136

Table 6.6 Correlation coefficients 